\title{
Treatment and Evaluation Advances in Leprosy Neuropathy
}

\author{
Gigi J. Ebenezer ${ }^{1}\left(\mathbb{D} \cdot\right.$ David M. Scollard $^{2}$
}

Accepted: 29 October 2021 / Published online: 19 November 2021

(c) The American Society for Experimental NeuroTherapeutics, Inc. 2021

\begin{abstract}
Neuropathy and related disabilities are the major medical consequences of leprosy, which remains a global medical concern. Despite major advances in understanding the mechanisms of $M$. leprae entry into peripheral nerves, most aspects of the pathogenesis of leprosy neuropathy remain poorly understood. Sensory loss is characteristic of leprosy, but neuropathic pain is sometimes observed. Effective anti-microbial therapy is available, but neuropathy remains a problem especially if diagnosis and treatment are delayed. Currently there is intense interest in post-exposure prophylaxis with single-dose rifampin in endemic areas, as well as with enhanced prophylactic regimens in some situations. Some degree of nerve involvement is seen in all cases and neuritis may occur in the absence of leprosy reactions, but acute neuritis commonly accompanies both Type 1 and Type 2 leprosy reactions and may be difficult to manage. A variety of established as well as new methods for the early diagnosis and assessment of leprosy neuropathy are reviewed. Corticosteroids offer the primary treatment for neuritis and for subclinical neuropathy in leprosy, but success is limited if nerve function impairment is present at the time of diagnosis. A candidate vaccine has shown apparent benefit in preventing nerve injury in the armadillo model. The development of new therapeutics for leprosy neuropathy is greatly needed.
\end{abstract}

Keywords Leprosy $\cdot$ Neuritis $\cdot$ M. leprae $\cdot$ Schwann cell $\cdot$ Rifampin $\cdot$ Armadillos

\section{Introduction}

Leprosy (Hansen's disease) remains a common infectious cause of neuropathy. The causative organisms are Mycobacterium leprae (M. leprae) and the more recently identified M. lepromatosis [1], now considered to be the M. leprae complex. M. leprae and M. lepromatosis are the only known species of mycobacteria that cannot be cultivated in vitro. They are obligate intracellular pathogens that prefer a low temperature $\left(33-34{ }^{\circ} \mathrm{C}\right)$. Growth in mouse footpads reveals a division time of approximately 13 days [2]. Although showing genomic differences, they cause the same symptoms, present the same clinical and pathological spectrum, and respond to the same anti-microbial drugs.

Leprosy produces a spectrum of disease that Ridley and Jopling classified into five types based on clinical,

Gigi J. Ebenezer

gebenezer@jhmi.edu

1 Neurology/Cutaneous Nerve Laboratory, Johns Hopkins University, The John G Rangos Bldg, room: 440, 855 North Wolfe Street, Baltimore, MD 21205, USA

2 National Hansen's Disease Programs, Baton Rouge, LA 70816, USA bacteriological, histological, and immunological features. M. leprae has a predilection for peripheral nerves and skin, and peripheral nerves are implicated across the spectrum of the disease[3, 4] (Fig. 1). The WHO classification defines only two types based primarily on the number of lesions: paucibacillary (PB) and multibacillary (MB) [5].

Leprosy neuritis widely differs based on the type of cellular inflammation of nerves and on the type of leprosy. In tuberculoid leprosy, ulnar and common peroneal nerves are typically affected. In lepromatous leprosy, the heavy bacterial load produces more diffuse involvement of the peripheral nerves and often presents with a symmetrical polyneuropathy. The facial and trigeminal nerves may also be involved. Larger nerves degenerate in more advanced stages, and motor manifestations occur during the latter stages of the disease.

The first neurological manifestation is often the development of sensory loss or paresthesia in one or more skin patches [6]. The patients are usually seen by general dermatologists, and often a delay in the diagnosis or misdiagnosis of leprosy neuropathy occurs. A substantial proportion of patients with leprosy have chronic grade 2 disabilities (visible impairments and deformities) at the time of their initial presentation $[7,8]$. Other than peripheral nerves in 
the skin, corneal nerves are known to undergo beading and thickening due to bacillary and inflammatory cell collections in and around the nerves of the stroma in lepromatous eyes impairing corneal sensation, promoting corneal ulceration and subsequent blindness [9-11].

\section{Neural Entry}

Possible routes of entry of $M$. leprae into the peripheral nerves are direct access to the terminal cutaneous nerves and a nasal route with vascular dissemination. Autopsy studies have shown that M. leprae bind to the exposed Remak Schwann cells in the papillary dermis and ascend directly from cutaneous nerves to the nerve trunks that carry both mixed sensory and motor nerve fibers trunks. There is possibility that the epidermis exposed to repeated abrasions at sites not protected especially the distal limbs [6, 12]. Bacteremia has been documented in lepromatous and borderline lepromatous leprosy [13, 14], possibly through the nasal entry, and the presence of $M$. leprae within endothelial cells has been well documented [15]. Studies have shown the presence of focal collections of M. leprae within epineural blood vessels and entry into the intraneural blood vessels in experimentally infected armadillos. Within the neural endoneurium, the bacilli are ingested by resident macrophages, or they may bind to the basal lamina of a Schwann cells, which then engulfs them and initiates cellular inflammatory episodes [16, 17].

\section{Leprosy Neuritis-Tissue Sites and Temperature}

Local factors play a major role in localizing the lesions. Brand observed that pathologic neural changes were concentrated in certain nerves and occur more frequently in areas where the peripheral nerves traverse joints, passing through unyielding fibro-osseous tunnels [18]. Leprosy preferentially involves superficially located nerves such as the facial, greater auricular, ulnar, median, radial, peroneal, and posterior tibial nerves. The superficial subcutaneous location of these nerves with relatively cooler tissue temperatures favors M. leprae proliferation [19, 20].

\section{Pathogenesis of Leprosy Neuritis}

$M$. leprae has a unique affinity for Schwann cells, and the Schwann cells serve as an important habitat for M. leprae in the midst of the cellular events that orchestrate nerve injury. An important advance made in the understanding of the pathogenesis of leprosy neuropathy has been the identification of host Schwann cell proteins that bind to M leprae. It has been shown that the organism binds to the $G$ domain of the laminin alpha- 2 chain which is expressed on the surface of the Schwann cell-axon unit through a receptor on $M$ leprae which has been shown to be a $21 \mathrm{kDa}$ histone-like protein. This protein, LBP21, coded by the ML1683 gene, is a major surface exposed antigen on M. leprae and probably serves as an adhesin for its interaction with peripheral nerves. Similarly, the terminal trisaccharide of phenolic glycolipid 1 (PGL-1) which is a surface exposed M. leprae specific antigen binds to laminin-2, indicating that PGL-1 also plays a part in the penetration of M. leprae into Schwann cells [21-24].

\section{Mechanisms Involved in Damage to the Peripheral Nerves}

1. Direct: M. leprae directly injure nerve fibers. Nonmyelinated Remak Schwann cells are highly susceptible to $M$. leprae colonization and multiplication (Fig. 2). Several different molecules on Schwann cells bind M. leprae and facilitate ingestion. Intraneural resident macrophages also engulf $M$. leprae and dwell in this intracytoplasmic milieu without evoking any inflammatory response (e.g., lepromatous leprosy). Based on innate and acquired immunity, a stepwise progression of neuritis occurs: stimulated by $M$. leprae, an immune-mediated inflammation triggered by T-cell/Schwann cell and macrophagic interactions, production of several proteins, a wide array of cytokines and chemokines resulting in macrophage and epithelioid granuloma formation, eventually disrupting and inducing axonal degeneration and demyelination (e.g., tuberculoid leprosy).

2. Indirect: A "bystander" type of nerve injury. Due to the large influx of cells and edema during the course of immune responses to $M$. leprae in type 1 reversal reactions [25-30].

Refer for further reading on pathogenesis of nerve damage in leprosy at https://internationaltextbookofleprosy.org.

\section{Clinical Presentation}

\section{Neuritis Associated with the Disease}

Peripheral nerves are infected with $M$. leprae very early in the course of the disease, possibly even before a cellular immune response (CMI) has developed. In a follow-up of a prospective cohort of 2664 new leprosy cases, $67 \%$ of multibacillary (MB) patients and $91 \%$ of paucibacillary (PB) patients developed nerve function impairment (NFI) during the first year of registration for therapy [31]. Since intraneural inflammatory lesions in leprosy are multifocal and patchy, the peripheral neuropathy of leprosy is classified as "mononeuritis multiplex." Mononeuritis affecting a single 
nerve without skin lesions are classified as "pure neuritic leprosy" [32-36]. Neuritis triggered by intraneural inflammatory response, edema, and granuloma formation clinically produces chronic low grade nerve pain.

A cross-sectional deep profiling study conducted in 86 patients with leprosy (with and without pain) using an extensive battery of phenotyping measures has shown that leprosy patients exhibit a profile of sensory loss to thermal and tactile stimuli combined but preserved vibration and deep pressure sensations. A high degree of impaired thermal sensation was found in subclinical neuropathy, a parameter that could be clinically implemented to enhance identification of leprosy neuropathy at an early stage [37].

\section{Acute Neuritis}

Acute neuritis in leprosy predominantly occurs in MB and borderline leprosy, commonly associated with type 1 and type 2 reactions. A change in immunological response to the bacteria can precipitate the type 1 reaction and can occur before starting, during, or after the completion of MDT. Increased T-cell reactivity to mycobacterial antigens is associated with the infiltration of interferon gamma (IFN$\gamma$ ) and TNF- $\alpha$ secreting CD-4-positive lymphocytes into the skin and nerves, resulting in edema and painful inflammation as well as an increase in serum cytokine concentration [38-40]. The onset of acute neuritis often starts with spontaneous nerve pain, paresthesia, and nerve tenderness. These symptoms are followed by nerve function impairment with sensory-motor loss.

\section{Silent Nerve Paralysis}

Silent nerve paralysis (SNP) is characterized by neurological deficit without any skin manifestations or nerve tenderness, and patients do not report with clinical symptoms. Studies have reported that when the functioning of the main peripheral nerve trunks known to be affected in leprosy was assessed using a nylon filament to test touch thresholds and a manual voluntary muscle test to quantify muscle strength, as many as $7 \%$ of newly presenting patients had silent nerve paralysis at their initial examination, and $75 \%$ of all silent nerve paralysis episodes occurred during the first year of MDT [41, 42].

\section{Subclinical Neuropathy}

Patients with leprosy skin lesions but with no clinical evidence of mechanosensory and/or motor impairment in an area of the hand innervated by one or more nerves, but having abnormal nerve conduction studies, are categorized as "subclinical neuropathy." To detect early detection of nerve impairment, one hundred and eighty-eight multibacillary
(MB) leprosy patients from a cohort of 303 were followed for 2 years, subclinical neuropathy was found to be extensive (20-50\%), and that was not evident when only Semmes-Weinstein monofilament testing (MFT) and voluntary muscle testing (VMT) were used [42, 43]. A detailed discussion of nerve function assessment in leprosy is available in recent guidelines published by the World Health Organization (WHO 2020) [44].

\section{Neuropathic Pain}

Pain is rarely recognized as a symptom in leprosy, as leprosy is well known to cause loss of sensation, disability, and disfigurement. Neuropathic pain in leprosy is not routinely investigated in population-based studies; however, recent studies have shown that neuropathic pain can develop several years after the completion of leprosy chemotherapy [45] and the prevalence of pain ranges from 11 to $66 \%$, probably due to differences in study design and clinical setting [45-47].

A recent study has reported that neuropathic pain in leprosy is as heterogeneous as neuropathic pain of other etiologies. Neuropathic pain in leprosy may respond to drugs usually used to control pain of neuropathic origin in general. Amitriptyline may be a potential candidate to be tested in clinical drug trials aimed at controlling neuropathic pain in leprosy [46].

\section{Treatment of Leprosy Neuritis}

Microscopic presence of M. leprae within nerves has been demonstrated in all types of leprosy. So, the management of leprosy neuritis are treatment of leprosy with MDT, treatment of type 1 and type 2 reactions, anti-inflammatory treatment, reconstructive surgeries, physiotherapy, and rest. Neuropathic pain may be treated with gabapentin or amitriptyline.

\section{Anti-bacterial Treatment}

Though the causative organism for leprosy M. leprae was demonstrated in 1873 by Armauer Hansen, the first medical treatment for leprosy was promin, a sodium glucosulfone introduced after half a century, in 1943. A few years later, a more effective oral long-term dapsone monotherapy against leprosy came into effect [48]. As resistance to this antibiotic was observed over the decades, newer drugs were subsequently identified and combined regimens recommended by the WHO [49-51]. The multidrug therapy (MDT) recommended in 1982 by the World Health Organization (WHO) as the standard treatment for leprosy is a combination of dapsone, rifampin, and clofazimine [5, 52] (Table 1). Antileprosy drugs have multiple targets in the leprosy bacillus, 
and MDT combination therapy is an effective means of curing the bacterial infection and lowering the risk of developing drug resistance. Notably, however, dead $M$. leprae are cleared from tissue very slowly, and the bacterial carcasses may therefore remain visible in biopsies for years after they have been killed. The antigens of these dead organisms may continue to elicit immunological and inflammatory responses [53, 54].

\section{Mode of Action of Multidrug Therapy}

\section{Dapsone}

Sulfone drugs target the dihydropteroate synthase (DHPS), a key enzyme in the folate biosynthesis pathway that is encoded by the folP gene. Dapsone is bacteriostatic, competitively inhibiting para-aminobenzoic acid (PABA), a critical substrate for folate biosynthesis. Dapsone has been shown to be effective in inhibiting the multiplication of M. leprae in both experimental mouse models and in humans [55-57].

\section{Rifampin}

Rifampin, a rifamycin derivative, is the key bactericidal component of the WHO-recommended MDT for leprosy treatment $[58,59]$. The target of rifampin in bacteria is the $\beta$-subunit of the DNA-dependent RNA polymerase, encoded by the rpoB gene. Rifampin interrupts the binding of the $\beta$-subunit with DNA, which uncouples the production of mRNA and results in the death of the organism. Rifampin has shown to be highly bactericidal in mice and humans, and experimental studies have shown no viable bacteria detected after MDT [60, 61], although recurrence of infection (either re-activation or re-infection) sometimes does occur [62].

\section{Clofazimine}

Clofazimine is a lipophilic riminophenazine compound and has antimycobacterial properties. Clofazimine is weakly bactericidal against $M$. leprae in the mouse model but has been used successfully as a combination therapy in the MDT for leprosy [63, 64]. Clofazimine also has anti-inflammatory effects that make it especially valuable in preventing or reducing the severity of type 2 (ENL) reactions in multibacillary patients.

Duration of Treatment The classification of patients for treatment and the duration of treatment with the WHO regimen have changed several times. The WHO originally recommended 24 months of MDT for MB patients, and the current recommended duration of treatment is 12 months, and the treatment regimen is given in Table 1. Recent trials from Bangladesh and Brazil have shown no relapse from patients treated with 6 or 12 months of WHO-recommended MDT or with uniform MDT regimen. The rate of decline of the BI was similar in the groups tested $[65,66]$. In a metaanalysis on twenty five studies conducted to evaluate the effectiveness on diverse treatment regimens, the WHO antibiotic regimen for leprosy was found to be the most effective treatment available so far [67].

The program for Global Sentinel Surveillance for drug resistance in leprosy was established by the WHO in 2009 to monitor drug resistance among patients of relapse http://apps. who.int/iris/handle/10665/205158. Although the prevalence of leprosy is declining, emergence of multidrug-resistant organisms have been documented over the decades in many dedicated leprosy centers equipped with mouse foot pad laboratories. Mutations associated with drug resistance have been identified for the folP, rpoB, and gyrA genes in M. leprae.

Table 1 WHO recommendations for multi-drug treatment of Hansen's disease

\begin{tabular}{|c|c|c|c|}
\hline \multirow[b]{2}{*}{ Drugs } & & \multicolumn{2}{|l|}{ WHO } \\
\hline & & Paucibacillary & Multibacillary \\
\hline \multirow[t]{3}{*}{ Dapsone } & Adult & $100 \mathrm{mg}$ daily & $100 \mathrm{mg}$ daily \\
\hline & Child (10-14 yrs.) & $50 \mathrm{mg}$ & $50 \mathrm{mg}$ \\
\hline & Child under 10 & $25 \mathrm{mg}$ & $25 \mathrm{mg}$ \\
\hline \multirow[t]{3}{*}{ Rifampin } & Adult & $600 \mathrm{mg}$ once/month & $600 \mathrm{mg}$ once/month \\
\hline & Child (10-14 yrs.) & $450 \mathrm{mg}$ once/month & $450 \mathrm{mg}$ once/month \\
\hline & Child under 10 & $300 \mathrm{mg}$ once/month & $300 \mathrm{mg}$ once/month \\
\hline \multirow[t]{3}{*}{ Clofazimine } & Adult & - & $50 \mathrm{mg}$ daily plus $300 \mathrm{mg}$ once/month \\
\hline & Child (10-14 yrs.) & - & $50 \mathrm{mg}$ daily plus $150 \mathrm{mg}$ once/month \\
\hline & Child under 10 & - & $50 \mathrm{mg}$ twice a week and $100 \mathrm{mg}$ once a month \\
\hline Duration (months) & & $\begin{array}{l}6 \text { doses ( } 6 \text { blisters) that can be } \\
\text { taken until } 9 \text { months }\end{array}$ & 12 doses ( 12 blisters) that can be taken until 9 months \\
\hline
\end{tabular}

In the USA, PB patients are treated with rifampin $600 \mathrm{mg}$ and dapsone $100 \mathrm{mg}$ daily for 12 months. MB patients are treated with rifampin $600 \mathrm{mg}$, clofazimine $50 \mathrm{mg}$ daily, and dapsone $100 \mathrm{mg}$ for 24 months 
As PCR testing for Mycobacterium leprae identification has been well established, routine monitoring for these mutations should be implemented during MDT surveillance and after completion of MDT [68-76].

\section{Alternative Treatment Regimens}

\section{Fluoroquinolones}

The target of fluoroquinolones is the DNA gyrase, a tetramer composed of two A-subunits (GyrA) and two B-subunits $(\mathrm{GyrB})$ and is required for the bacterial DNA replication. Among the fluoroquinolones, moxifloxacin has shown to be a powerful bactericidal agent and have been shown to inhibit the $M$. leprae DNA gyrase at concentrations similar to those necessary to inhibit the M. tuberculosis gyrase. Ofloxacin is a fluorinated carboxyquinalone, and studies in lepromatous leprosy patients have demonstrated bactericidal activity killing $99.99 \%$ of viable bacteria but not acceptable as a single drug due to side effects in human [77-79].

\section{Macrolides}

Clarithromycin is the only macrolide that displays significant bactericidal activity against $M$. leprae, inhibiting protein synthesis by binding to the 50S subunit of the mycobacterial ribosome, targeting 23S rRNA of the bacteria. Clarithromycin at an estimated MIC of $0.12 \mu \mathrm{g} / \mathrm{ml}$ in mouse experiments found to have potent M. leprae activity. Clarithromycin has also been shown to be bactericidal in humans, where the daily administration of $500 \mathrm{mg}$ of clarithromycin killed $99 \%$ of viable $M$. leprae within 28 days and $99.9 \%$ by 56 days [80-82].

\section{Tetracycline}

Tetracyclines inhibit protein synthesis and bind reversibly to the 30S ribosomal subunit, blocking the binding of aminoacyltRNA to the $16 \mathrm{~S}$ rRNA-ribosome complex of bacteria. Minocycline is the only tetracycline effective against $M$. leprae, and it is bactericidal. Its lipophilic nature probably enhances cell wall penetration. Minocycline has shown to have an additive effect when given with clarithromycin either in a single or in multiple doses. Minocycline has also shown good companion drug activity when combined with other drugs, especially in combination with rifampin + ofloxacin + minocycline (ROM) combination, or with another fluoroquinolone, in the rifapentine + moxifloxacin + minocycline $(\mathrm{PMM})$ combination [83-86].

To further improve the efficacy of treatment and reduce the duration of treatment, several drugs have undergone research trials with rifampin as one of the components to achieve a better cure for leprosy. However, none of the trials particularly analyzed the efficacy of the drugs on nerve functions to manage neuropathy.

The WHO 7th expert committee (1997) recommended the use of single dose of rifampin $(600 \mathrm{mg})+$ ofloxacin $(400 \mathrm{mg})+$ minocycline $(100 \mathrm{mg})$ for single lesion and two or three PB lesions. ROM combinations underwent multicentric randomized double-blind control trials. A systematic review has assessed 14 studies comparing ROM with MDT, and both groups had a similar fall in BI (3.5 to 2.5) after 24 months of treatment, as well as similar clinical and histological improvements [86-90]. For operational reasons, ROM therapy has been withdrawn from routine implementation as a therapy for paucibacillary leprosy.

\section{Chemoprophylaxis}

Probably the most active area of current research with respect to leprosy treatment is the evaluation of post-exposure chemoprophylaxis (PEP) with single-dose rifampin (SDR). A cluster-randomized, placebo-controlled trial in Bangladesh evaluated 21,711 contacts of 1037 patients receiving either $150 \mathrm{mg}$ rifampin or placebo and followed up for 4 years [91]. Results revealed an overall $57 \%$ reduction in new cases at 2 years among recipients of SDR-PEP vs placebo, but no difference at 4 years. The benefits were greatest among neighbors and social contacts but were minimal among household contacts. SDR-PEP and contact tracing have been enthusiastically embraced by the WHO (WHO; https://www. who.int/docs/default-source/ntds/leprosy/global-consultationon-global-leprosy-strategy-2021-2030/10-contact-trace-pepwho-guidance.pdf, accessed 23-6-2021) and by many national programs [92], but some experts remain strongly critical [93].

To attempt to achieve better protection among household contacts, an enhanced, a 3 dose regimen of rifampin and moxifloxacin $(\mathrm{PEP}++)$, has been recommended by a study group [94]. After the European Medicines Agency issued a warning regarding the use of minocycline, the $\mathrm{PEP}++$ regimen was modified to rifampin + clarithromycin (Wim van Brakel, personal communication), and a multi-center trial is underway.

\section{Anti-inflammatory Treatment}

Though MDT kill bacteria and reduce the antigenic burden responsible for the reactions and neuritis, corticosteroids play the most vital role as an anti-inflammatory therapy for the management of neuritis.

\section{Corticosteroids in Leprosy}

Mechanism of action: Corticosteroids have both antiinflammatory and immunosuppressive actions and exert their actions through classic genomic and non-genomic pathways 
$[95,96]$. The strong anti-inflammatory and immunosuppressive effects of glucocorticoids are mediated primarily by the cytosolic glucocorticoid receptors. These receptors are members of the steroid hormone receptor family, a superfamily of ligand-inducible transcription factors, and exert genomic effects that can result in increased expression of anti-inflammatory or decreased production of proinflammatory proteins. The non-genomic effects were mediated (in part) by the same glucocorticoid receptors, as well as by other specific membrane interactions [97, 98].

\section{Steroids in Leprosy Reactions}

Prednisolone is generally considered an important drug for improving nerve function impairment (NFI). However, optimal dose and duration of prednisolone treatment has not been established yet. The WHO recommends a standard field regimen of 12 weeks of steroid therapy to treat acute neuritis and starts with $40 \mathrm{mg}$ of prednisolone and tapered over the next 12 weeks. Rao et al.compared three steroid regimens in leprosy patients with type 1 reaction (T1R) and concluded that prolonged duration of therapy ( 5 months) is more effective than shorter duration (3 months) and initial high-dose therapy, as TIR persist over many months [99]. Various studies lend further support to the use of more prolonged courses of steroid for the treatment of T1R [100-102].

When high dose $(60 \mathrm{mg})$ was compared with low dose $(40 \mathrm{mg}$ ) in the management of T1R, recurrence noted was $16 \%$ and $48.3 \%$, respectively, and both regimens were effective, but the majority of the recurrences of reaction occurred within a period of 6 months after completion of the low-dose regimen [103].

\section{Steroids in Acute and Chronic Neuritis}

Observational studies in leprosy neuropathy have shown that prednisolone improves nerve function [99, 104, 105]. The effects of steroids on neuritis have been analyzed in a few large longitudinal field evaluation studies and have shown varied responses probably due to varied research settings, inclusion criteria, and treatment regimens.

In a retrospective cohort study at Nepal, when one hundred and sixty-eight leprosy patients were treated with one of four different corticosteroid regimens for impairment of nerve function, nerve function improved in 30-84\% (depending on the type of nerve) of patients. The study concluded that improvement was directly related to the severity of the nerve damage observed at the beginning of treatment [106].

Analysis across studies indicates that a high proportion of patients (33-75\%) experience spontaneous nerve function improvement even if left untreated based on the severity of NFI and type of nerve. This has become a major confounding factor in determining the duration and dosage for the steroid treatment. At the ALERT MDT Field Evaluation Study, 300 multibacillary (MB) and 294 paucibacillary (PB) cases were followed over a period of 10 years. Two steroid regimens were used, both starting with $40 \mathrm{mg}$ of prednisolone daily and decreasing regularly: for multibacillary patients, the treatment continued for 24 weeks and for paucibacillary patients for 12 weeks only. In patients with no impairment at the start of the study, treatment with steroids resulted in full recovery in $88 \%$ of nerves with acute neuropathy but only $51 \%$ of those with chronic or recurrent neuropathy. The median time to full recovery from acute neuropathy was approximately 6 months. Of nerves with acute neuropathy that were not treated with steroids, $42 \%$ were found to have fully recovered [104].

In a multicenter, randomized, double-blind placebocontrolled trial conducted in Nepal and Bangladesh, $92 \mathrm{MB}$ patients with untreated NFI between 6- and 24-month duration were given the standard corticosteroid therapy regimen; prednisolone treatment starting at $40 \mathrm{mg} /$ day, tapered by $5 \mathrm{mg}$ every 2 weeks, and completed after 16 weeks. The results revealed that prednisolone did not provide any additional nerve function improvement in comparison to placebo group nor did it prevent further leprosy reactions. The trial highlights the spontaneous recovery of nerve function without steroid treatment and the importance of not to treat long-standing NFI with prednisolone [107].

In a randomized controlled trial, the effectiveness of the duration of steroid treatment on nerve function impairment was tested. The group concluded that a 20 -week course of prednisolone was as effective as a 32-week course to improve and restore the recent-onset clinical NFI in leprosy patients [108].

The addition of low-dose prophylactic prednisolone with multidrug treatment for leprosy reduced the incidence of new reactions and nerve function impairment in the short term, but the effect was not a sustainable long term [109]. The long-term use of corticosteroids for the control of leprosy reactions with neuritis (see below) increases the risk of serious morbidity from the side effects of these drugs [110]. As a result, there is increased interest in the use of steroidsparing agents such as methotrexate [111].

\section{Other Anti-inflammatory Agents}

Other than prednisolone, no other drugs has been proven to be effective for NFI. Clofazimine and thalidomide have been used in the treatment of leprosy reactions but have shown to produce significant adverse effects when given for longer durations [112]. Immunosuppressants like azathioprine and cyclosporine for the treatment of reactions have been shown not to have any specific improvement on NFI [113-117]. 


\section{Non-pharmacological Considerations in Management of Neuritis}

Guidance from the WHO [44] recommends that in addition to the use of anti-inflammatory agents, the treatment of neuritis - alone or as part of leprosy reactions - should also include the following:

1. Resting of the affected limb, possibly including splinting at night

2. In the post-acute phase, passive stretching of weakened muscles and active exercises to strengthen them

3. Moisturizing and oiling dry skin to minimize cracking and prevent superficial wounds

\section{Reversal (Type 1) Reactions and Treatment}

Reversal reactions occur among patients in the broad borderline portion of the leprosy spectrum, from borderline tuberculoid to borderline lepromatous. They are characterized by the insidious onset of exacerbation of existing cutaneous lesions which become indurated and erythematous, often with acute neuritis, accompanied by fever and malaise. They may occur before, during, or after MDT; when they develop after initiation of treatment, patients (and inexperienced physicians) often are alarmed that the treatment has "made the disease worse." Reversal reactions result from spontaneous enhancement of the Th1 cell-mediated immune response to M. leprae. The inciting factors are usually unknown, but it is notable that reversal reactions have been observed as an immune reconstitution inflammatory syndrome (IRIS) in patients with leprosy after discontinuation of infliximab [118] as well as in patients coinfected with HIV after initiation of antiviral treatment [119].

\section{ENL (Type 2 reactions) and Treatment}

ENL occurs in lepromatous leprosy and borderline-lepromatous patients. The reaction can manifest even years after completion of treatment. Patients present with fever and crops of small pink skin nodules. The other signs are iritis, neuritis, lymphadenitis, orchitis, bone pain, dactylitis, arthritis, and proteinuria. Cutaneous ENL lesions are characterized by an influx of polymorphs, and patients have very high circulating levels of TNF $\alpha$. The immunological mechanism responsible for the symptoms and signs is widely considered to be a systemic inflammatory response to the deposition of extravascular immune complexes. Thalidomide ( $400 \mathrm{mg}$ daily) is the drug of choice for treatment (mainly in young men), but because of the risk of birth defects and the resulting restrictions and difficulties in using thalidomide, corticosteroids, with or without a high dose of clofazimine, are more frequently used. Small clinical trials have shown that methotrexate administered with low-dose corticosteroids is effective and safe as a corticosteroid-sparing agent. Pentoxifylline, which inhibits tumor necrosis factor (TNF) production, has also been used to treat ENL [120-123]. Inhibitors of TNF $\alpha$ such as infliximab have been used in cases of severe ENL refractory to other agents [124].

\section{Leprosy Vaccine}

Because of the dormant nature of $M$. leprae, the long incubation period, effective treatment with MDT, low prevalence of the disease, and poor funding resources, vaccine development has taken a backseat, and only a few vaccines have been developed over the last half a century. Both live attenuated (BCG) and killed mycobacteria vaccines have been generally well tolerated, and both BCG and Mycobacterium indicus pranii (MIP) have a potential immunoprophylactic role against leprosy and tuberculosis [125-127]. However, the effect of vaccination on M. leprae-associated neuropathy has not been investigated or carefully analyzed in any multicentric post-vaccination followup trials, although there is evidence that a small set of BCG recipients have precipitated PB leprosy [128, 129]

A major breakthrough in the development of vaccine candidates against intracellular $M$. leprae occurred with the identification of adjuvants capable of stimulating macrophages and dendritic cells inducing Th1 responses. This has resulted in developing a new generation of T-cell vaccines. Another major advancement is the development of new adjuvants using formulated TLR ligands (TLRL), designing and optimizing a new generation of ligands.

When mice were immunized with LEP-F1 (a single tetravalent $89 \mathrm{kD}$ fusion protein, designated Lep-F1 with a cocktail of ML2055, ML2380, and ML2028 antigens) in conjunction with glucopyranosyl lipid adjuvant in stable emulsion GLA-SE (LepVax), the M. leprae infection levels was reduced [130-133]. To further understand effect of immunization on M. leprae-associated neuropathy, the vaccine LepVax was tested in Armadillos, an experimental animal model for lepromatous neuropathy. The study provided evidence that provision of LepVax after M. leprae infection (post-exposure immunoprophylaxis) was not only safe but effective, reducing sensory nerve damage and delaying motor nerve damage in animals infected with high doses of M. leprae. LepVax that underwent experimental trials have advanced to a phase 1 , open-label clinical trial in healthy adult subjects $[134,135]$.

\section{Diagnostic Techniques for Leprosy Neuropathy}

The WHO expert committee on leprosy (8th report) has defined a case of leprosy as an individual who has one of the following cardinal signs of leprosy: 


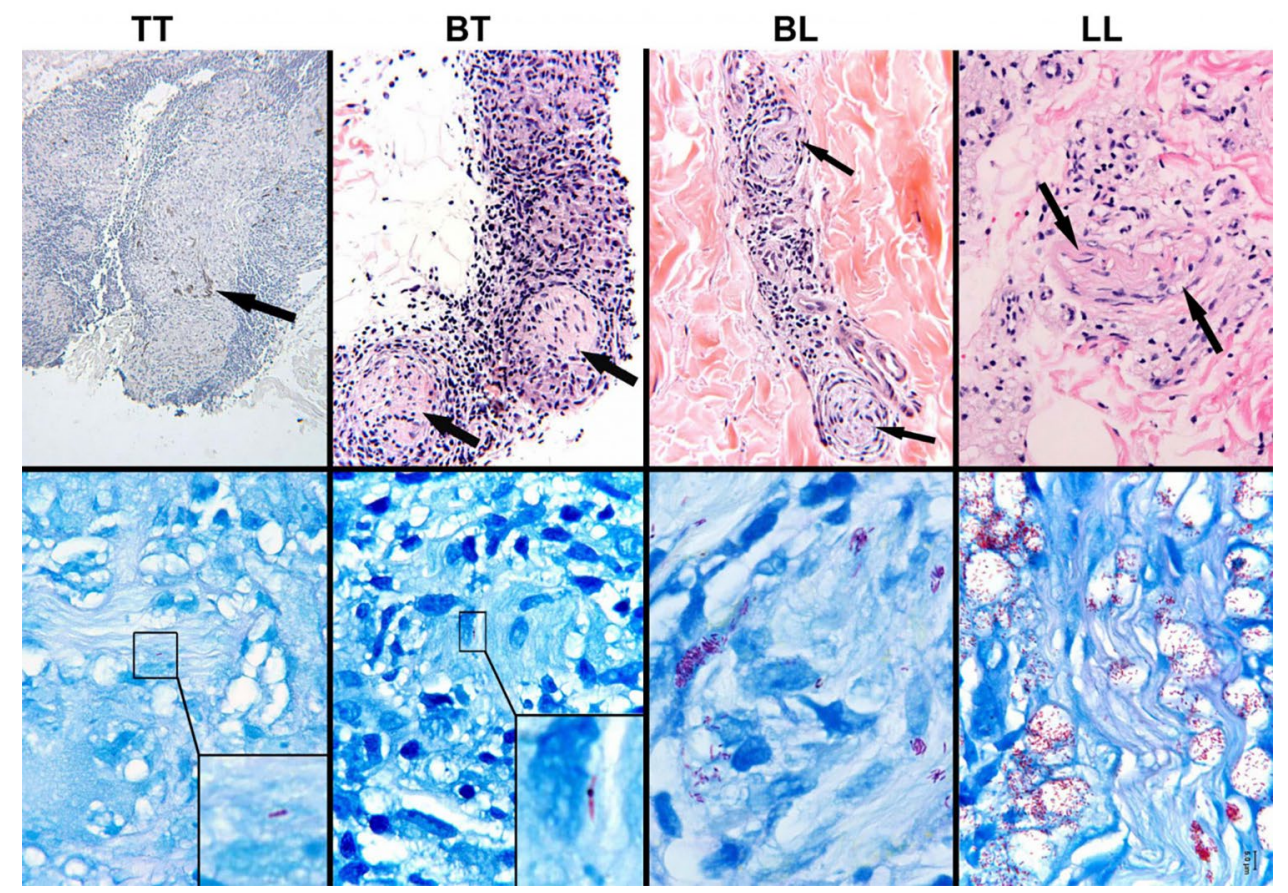

Fig. 1 Inflammation and infection of cutaneous nerves across the leprosy spectrum. The inflammatory responses in and around cutaneous nerves are shown in the upper panel; arrows highlight recognizable nerve twigs. The immunopathologic classifications of leprosy, TT to $\mathrm{LL}$, are indicated at the top of the figure (see text; mid-borderline, $\mathrm{BB}$, is not shown). The TT lesion (upper left) is composed of a wellorganized epithelioid granuloma that has nearly destroyed the nerve, remnants of which are shown by S-100 staining. The granulomatous inflammatory response becomes less organized across the spectrum until, at the LL extreme, it is composed of disorganized aggregates of foamy histiocytes, seen here surrounding a nerve (upper right). (TT,

- A definite loss of sensation in a pale (hypopigmented) or reddish skin patch

- A thickened or enlarged peripheral nerve with a loss of sensation and/or weakness in the muscles supplied by the nerve

- The presence of acid-fast bacilli in a slit-skin smear (SSS)

The above-mentioned cardinal signs can be tested by the following methods:

\section{Nerve Biopsy}

The nerves usually chosen for biopsy are a branch of sural nerve at the level just above the ankle or a branch of the radial cutaneous nerve at the wrist region. In the tuberculoid spectrum of disease, a cutaneous nerve adjacent to a skin if enlarged may be chosen for biopsy.

The following are well-established techniques that are available to examine histopathological changes in leprosy affected nerves:
S-100, original magnification $\times 10$; BT, BL, LL, hematoxylin-eosin, original magnification $\times 250$ ). The demonstration of acid-fast bacilli within nerves is pathognomonic of leprosy. In the lower panel, Fitestained sections reveal the corresponding intensity of $\mathrm{M}$ leprae infection in cutaneous nerves across the spectrum. M. leprae are rare and difficult to demonstrate in nerves of TT and BT lesions; they have been photographically enlarged in the insets. In contrast, bacilli are abundant and easily recognized in BL and LL lesions. (Fite/methylene blue, original magnification $\times 1000$.) (From Scollard et al., The Continuing Challenges of Leprosy. 2006. Clinical Microbiology Reviews, 19: 338-381

1. Job-Chacko modification of Fite-Faraco stain for AFB* [136]

2. Gomori's-Grocott methanamine silver stain to demonstrate remnants of M. leprae

3. Luxol fast blue stain for myelin

4. Van Gieson's stain for collagen fibers

5. Bodian's silver stain for axons

6. Immunohistochemical stains for nerves: antibodies to PGP9.5 to identify axons, S-100 and nerve growth factor receptor (p75) for Schwann cells and myelin basic protein for myelin

7. Immunohistochemistry and immunofluorescent microscopy to demonstrate mycobacterial antigens

8. In situ hybridization and PCR studies

*Note: M. leprae is weakly acid-fast and standard Ziehl-Neelsen staining may not demonstrate all organisms.

In the histopathological work up, finding M. leprae in tissues and/or granulomatous destruction of nerves are the two important findings in confirming leprosy diagnosis (Fig. 1). Immunohistochemical staining of M. leprae, nerve 

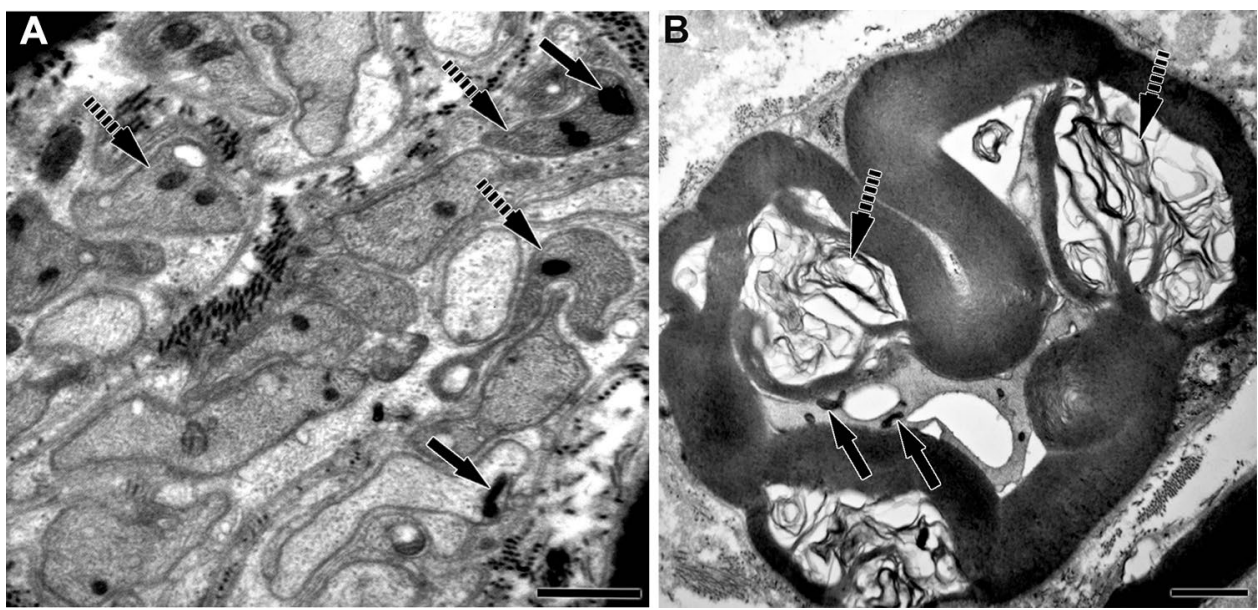

Fig. 2 Electron micrographs of Mycobacterium leprae-infected peripheral nerves of Armadillos. A Electron micrograph of a $M$. leprae-infected tibial nerve section containing Remak bundles (unmyelinated axons) with $M$. leprae (arrows) in axoplasm and Schwann cell cytoplasm. Many Schwann cell process are dener-

components, PCR amplification of M. leprae DNA, and whole-genome analysis have enhanced the sensitivity of histopathological diagnosis though the usage is limited by cost and availability of specialized equipment in low-resourced countries. Electron microscopic studies have been extensively used to localize the $M$. leprae organisms in quantitative experimental research studies [32, 134, 137-145].

\section{Skin Biopsy to Evaluate Epidermal Nerve Fibers}

Quantification of intraepidermal nerve fibers (IENF) in skin biopsies has emerged as a standard and sensitive clinical tool to diagnose small fiber sensory neuropathy and many academic groups in western countries now routinely perform IENF analysis as the primary morphologic indicator of sensory nerve damage and as a research tool in experimental animal models [142, 146-148].

A major challenge in leprosy endemic countries is to detect early leprosy skin lesions that mimic other dermatological lesions. Over the decades, a few studies have reported early disappearance of neuropeptide immunoreactivity in leprosy lesions and loss of epidermal nerve fibers in distal extremities [134, 149-152]. This technique can be utilized in leprosy hands and feet to evaluate autonomic fiber involvement and regenerative effort of fibers during and after multidrug therapy.

\section{Neurophysiological Studies}

The standard routine examination to assess nerve function impairment in leprosy neuropathy is done in the hands, feet, vated (broken arrows) but contain $M$. leprae. Scale bar: A $=1 \mu \mathrm{m}$. B Cross section of a myelinated axon with $M$. leprae within axoplasm (arrows). The nerve shows extensive demyelination (broken arrows) and axonal disruption. Scale bar: $\mathrm{B}=2 \mu \mathrm{m}$

and eyes. However, evaluation of facial cutaneous sensation is not routinely performed.

The nerve function evaluation techniques tested in leprosy neuropathy include nerve conduction studies (NCS), quantitative sensory test (QST), tactile sensitivity of skin lesions assessment with Semmes-Weinstein MFT or ballpoint tests, and motor function assessment with voluntary muscle tests. Conventional electrophysiological recording generally involves evaluation of median, ulnar, radial, tibial, and common peroneal nerves.

Nerve conduction studies have demonstrated predominantly axonal neuropathy in leprosy, i.e., reduction in sensory nerve action potential (SNAP) and compound muscle action potential (CMAP) amplitude. Sensory nerves are more commonly affected than motor, and SNAP amplitudes are altered more than CMAP. Nerve conduction was found to be affected most frequently, followed by warm detection thresholds (WDT) with QST. These two methods were able to detect abnormalities in the nerves up to 12 weeks before MFT becomes abnormal. Multibacillary leprosy patients had significantly more severe changes in nerve conduction parameters compared with paucibacillary leprosy. The lower extremity was more frequently and severely involved than the upper limbs in both groups of patients [153-160].

\section{High-Resolution Ultrasonography with Color Doppler}

Recently, high-frequency ultrasound with color Doppler (HFUS with CD) have been used to describe characteristic changes in leprosy neuropathy to further facilitate diagnosis and treatment. Studies have described nerve thickening at entrapment sites, cross-sectional area difference between 
tuberculoid and lepromatous diseases, and increased intraneural or perineural vascularization [161-165].

Laser Doppler and infrared thermography are other techniques used to investigate autonomic fiber involvement in leprosy. Some small studies have documented a high prevalence of autonomic dysfunction in newly diagnosed leprosy patients [166-168].

\section{Conclusion}

The introduction of MDT has reduced the prevalence of leprosy over the decades, and patients who have completed treatment are considered as bacteriologically cured of $M$. leprae infection. However, the nerve damage caused by $M$. leprae leaves many patients living with impaired sensation and physical deformities. Tremendous progress has been made in the field of $M$. leprae gene sequencing, diagnostic advances to identify nerve damage and vaccine development. The only animal model of leprosy neuropathy, the nine-banded armadillo, has been shown to be an excellent experimental model to test newer therapeutic drugs and has given us a tool to stimulate and modulate regeneration of nerve fibers. A great need exists for the development of new agents for the treatment of neuropathy in leprosy.

Supplementary Information The online version contains supplementary material available at https://doi.org/10.1007/s13311-021-01153-z.

Acknowledgements The authors thank L. Crabtree and K. Wagner for excellent administrative and technical assistance, Cutaneous Nerve Laboratory (research), Neurology, Johns Hopkins School of Medicine.

Required Author Forms Disclosure forms provided by the authors are available with the online version of this article.

\section{References}

1. Han, X.Y., Y.H. Seo, K.C. Sizer, T. Schoberle, G.S. May, J.S. Spencer, et al. A new Mycobacterium species causing diffuse lepromatous leprosy. Am J Clin Pathol 2008;130:(6):856-64.

2. Sharma, R., P. Singh, R.C. McCoy, S.M. Lenz, K. Donovan, M.T. Ochoa, et al. Isolation of Mycobacterium lepromatosis and Development of Molecular Diagnostic Assays to Distinguish Mycobacterium leprae and M. lepromatosis. Clin Infect Dis 2020;71:(8):e262-e269.

3. Ridley, D.S. Histological classification and the immunological spectrum of leprosy. Bull World Health Organ 1974;51:(5):451-65.

4. Ridley, D.S. and W.H. Jopling. Classification of leprosy according to immunity. A five-group system. Int J Lepr Other Mycobact Dis 1966;34:(3):255-73.

5. WHO Expert Committee on Leprosy., WHO Expert Committee on Leprosy : sixth report. World Health Organization technical report series,. 1988, Geneva: World Health Organization. 51 p.

6. Dastur, D.K. Cutaneous nerves in leprosy; the relationship between histopathology and cutaneous sensibility. Brain 1955;78:(4):615-33.
7. Srinivas, G., T. Muthuvel, V. Lal, K. Vaikundanathan, E.M. Schwienhorst-Stich, and C. Kasang. Risk of disability among adult leprosy cases and determinants of delay in diagnosis in five states of India: A case-control study. PLoS Negl Trop Dis 2019;13:(6):e0007495.

8. Moschioni, C., C.M. Antunes, M.A. Grossi, and J.R. Lambertucci. Risk factors for physical disability at diagnosis of 19,283 new cases of leprosy. Rev Soc Bras Med Trop 2010;43:(1):19-22.

9. Daniel, E., T.J. Ffytche, J.H. Kempen, P.S. Rao, M. Diener-West, and P. Courtright. Incidence of ocular complications in patients with multibacillary leprosy after completion of a 2 year course of multidrug therapy. Br J Ophthalmol 2006;90:(8):949-54.

10. Ebenezer, G.J. and E. Daniel. Expression of protein gene product 9.5 in lepromatous eyes showing ciliary body nerve damage and a "dying back" phenomenon in the posterior ciliary nerves. Br J Ophthalmol 2004;88:(2):178-81.

11. Zhao, C., S. Lu, N. Tajouri, A. Dosso, and A.B. Safran. In vivo confocal laser scanning microscopy of corneal nerves in leprosy. Arch Ophthalmol 2008;126:(2):282-4.

12. Ebenezer, G.J., S. Arumugam, and C.K. Job. Infection by M. leprae is governed by the temperature at the entry point: a preliminary note. Int J Lepr Other Mycobact Dis 1999;67:(2):162-4.

13. Drutz, D.J., T.S. Chen, and W.H. Lu. The continuous bacteremia of lepromatous leprosy. N Engl J Med 1972;287:(4):159-64.

14. Raval, S.N., U. Sengupta, G. Ramu, P.V. Prabhune, and K.V. Desikan. A study of continuous bacillaemia in borderline and lepromatous type of leprosy. Lepr India 1982;54:(4):623-33.

15. McDougall, A.C., R.J. Rees, A.G. Weddell, and M.W. Kanan. The histopathology of lepromatous leprosy in the nose. J Pathol 1975;115:(4):215-26.

16. Scollard, D.M. Endothelial cells and the pathogenesis of lepromatous neuritis:insights from the armadillo model. Microbes Infect 2000;2:(15):1835-43.

17. Scollard, D.M., G. McCormick, and J.L. Allen. Localization of Mycobacterium leprae to endothelial cells of epineurial and perineurial blood vessels and lymphatics. Am J Pathol 1999;154:(5):1611-20.

18. Brand, P.W. Temperature variation and leprosy deformity. Int J Lepr 1959;27:(1):1-7.

19. Hastings, R.C., P.W. Brand, R.E. Mansfield, and J.D. Ebner Bacterial density in the skin in lepromatous leprosy as related to temperature. Lepr Rev 1968;39:(2):71-4.

20. Sabin, T.D., E.R. Hackett, and P.W. Brand. Temperatures along the course of certain nerves often affected in lepromatous leprosy. Int J Lepr Other Mycobact Dis 1974;42:(1):38-42.

21. Rambukkana, A. Molecular basis for the peripheral nerve predilection of Mycobacterium leprae. Curr Opin Microbiol 2001;4:(1):21-7.

22. Rambukkana, A., J.L. Salzer, P.D. Yurchenco, and E.I. Tuomanen. Neural targeting of Mycobacterium leprae mediated by the $\mathrm{G}$ domain of the laminin-alpha2 chain. Cell 1997;88:(6):811-21.

23. Rambukkana, A., H. Yamada, G. Zanazzi, T. Mathus, J.L. Salzer, P.D. Yurchenco, et al. Role of alpha-dystroglycan as a Schwann cell receptor for Mycobacterium leprae. Science 1998;282:(5396):2076-9.

24. Hess, S. and A. Rambukkana. Cell Biology of Intracellular Adaptation of Mycobacterium leprae in the Peripheral Nervous System. Microbiol Spectr 2019;7:(4).

25. Spierings, E., T. De Boer, L. Zulianello, and T.H. Ottenhoff. Novel mechanisms in the immunopathogenesis of leprosy nerve damage: the role of Schwann cells, T cells and Mycobacterium leprae. Immunol Cell Biol 2000;78:(4):349-55.

26. Rambukkana, A. Mycobacterium leprae-induced demyelination: a model for early nerve degeneration. Curr Opin Immunol 2004;16:(4):511-8. 
27. Chandi, S.M. and C.K. Job. The early cellular response to M. leprae. An ultrastructural study. Lepr India 1978;50:(3):345-57.

28. Sherman, D.L., C. Fabrizi, C.S. Gillespie, and P.J. Brophy. Specific disruption of a schwann cell dystrophin-related protein complex in a demyelinating neuropathy. Neuron 2001;30:(3):677-87.

29. Madigan, C.A., C.J. Cambier, K.M. Kelly-Scumpia, P.O. Scumpia, T.Y. Cheng, J. Zailaa, et al. A Macrophage Response to Mycobacterium leprae Phenolic Glycolipid Initiates Nerve Damage in Leprosy. Cell 2017;170:(5):973-985 e10.

30. Oliveira, A.L., S.L. Antunes, R.M. Teles, A.C. Costa da Silva, T.P. Silva, R. Brandao Teles, et al. Schwann cells producing matrix metalloproteinases under Mycobacterium leprae stimulation may play a role in the outcome of leprous neuropathy. $\mathrm{J}$ Neuropathol Exp Neurol 2010;69:(1):27-39.

31. Croft, R.P., P.G. Nicholls, J.H. Richardus, and W.C. Smith. Incidence rates of acute nerve function impairment in leprosy: a prospective cohort analysis after 24 months (The Bangladesh Acute Nerve Damage Study). Lepr Rev 2000;71:(1):18-33.

32. Scollard, D.M., R.W. Truman, and G.J. Ebenezer. Mechanisms of nerve injury in leprosy. Clin Dermatol 2015;33:(1):46-54.

33. Chandi, S.M., C.J. Chacko, E.P. Fritschi, and C.K. Job. Segmental necrotizing granulomatous neuritis of leprosy. Int J Lepr Other Mycobact Dis 1980;48:(1):41-7.

34. Santos, D.F.D., M.R. Mendonca, D.E. Antunes, E.F.P. Sabino, R.C. Pereira, L.R. Goulart, et al. Revisiting primary neural leprosy: Clinical, serological, molecular, and neurophysiological aspects. PLoS Negl Trop Dis 2017;11:(11):e0006086.

35. Serrano-Coll, H., O. Mieles, C. Escorcia, A. Diaz, C. Beltran, and N. Cardona-Castro. [A case series of pure neural leprosy in patients diagnosed in a specialized center for the control of Hansen's disease in Colombia]. Biomedica 2018;38:(2):153-161.

36. Shukla, B., R. Verma, V. Kumar, M. Kumar, K.P. Malhotra, R.K. Garg, et al. Pathological, ultrasonographic, and electrophysiological characterization of clinically diagnosed cases of pure neuritic leprosy. J Peripher Nerv Syst 2020;25:(2):191-203.

37. Haroun, O.M.O., J. Vollert, D.N. Lockwood, D.L.H. Bennett, V.V. Pai, V. Shetty, et al. Clinical characteristics of neuropathic pain in leprosy and associated somatosensory profiles: a deep phenotyping study in India. Pain Rep 2019;4:(6):e743.

38. van Brakel, W.H., P.G. Nicholls, L. Das, P. Barkataki, S.K. Suneetha, R.S. Jadhav, et al. The INFIR Cohort Study: investigating prediction, detection and pathogenesis of neuropathy and reactions in leprosy. Methods and baseline results of a cohort of multibacillary leprosy patients in north India. Lepr Rev 2005;76:(1):14-34.

39. Saunderson, P. The epidemiology of reactions and nerve damage. Lepr Rev 2000;71 SupplS106-10.

40. Scollard, D.M., C.M. Martelli, M.M. Stefani, F. Maroja Mde, L. Villahermosa, F. Pardillo, et al. Risk factors for leprosy reactions in three endemic countries. Am J Trop Med Hyg 2015;92:(1):108-14.

41. van Brakel, W.H. and I.B. Khawas. Silent neuropathy in leprosy: an epidemiological description. Lepr Rev 1994;65:(4):350-60.

42. van Brakel, W.H., P.G. Nicholls, E.P. Wilder-Smith, L. Das, P. Barkataki, D.N. Lockwood, et al. Early diagnosis of neuropathy in leprosy--comparing diagnostic tests in a large prospective study (the INFIR cohort study). PLoS Negl Trop Dis 2008;2:(4):e212.

43. Wagenaar, I., W. Brandsma, E. Post, W. van Brakel, D. Lockwood, P. Nicholls, et al. Two randomized controlled clinical trials to study the effectiveness of prednisolone treatment in preventing and restoring clinical nerve function loss in leprosy: the TENLEP study protocols. BMC Neurol 2012;12159.

44. Cooreman, E.A., Leprosy/Hansen Disease: Management of reactions and prevention of disabilities. 2020: World Health Organization. 72 .
45. Haroun, O.M.O., A. Hietaharju, E. Bizuneh, F. Tesfaye, W.J. Brandsma, M. Haanpaa, et al. Investigation of neuropathic pain in treated leprosy patients in Ethiopia: a cross-sectional study. Pain 2012;153:(8):1620-1624.

46. Raicher, I., P. Stump, S.B. Harnik, R.A. de Oliveira, R. Baccarelli, L. Marciano, et al. Neuropathic pain in leprosy: symptom profile characterization and comparison with neuropathic pain of other etiologies. Pain Rep 2018;3:(2):e638.

47. Lasry-Levy, E., A. Hietaharju, V. Pai, R. Ganapati, A.S. Rice, M. Haanpaa, et al. Neuropathic pain and psychological morbidity in patients with treated leprosy: a cross-sectional prevalence study in Mumbai. PLoS Negl Trop Dis 2011;5:(3):e981.

48. Faget, G.H. and P.T. Erickson. Leprosy chemotherapy. Am Clin 1948;12:(6):503-10.

49. Alemu Belachew, W. and B. Naafs. Position statement: LEPROSY: Diagnosis, treatment and follow-up. J Eur Acad Dermatol Venereol 2019;33:(7):1205-1213.

50. Lowe, J. Treatment of leprosy with diamino-diphenyl sulphone by mouth. Lancet 1950;1:(6596):145-50.

51. Pearson, J.M., R.J. Rees, and M.F. Waters. Sulphone resistance in leprosy. A review of one hundred proven clinical cases. Lancet 1975;2:(7924):69-72.

52. WHO Study Group on Chemotherapy of Leprosy. and World Health Organization., Chemotherapy of leprosy : report of a WHO study group. WHO technical report series,. 1994, Geneva: World Health Organization. v, 24 p.

53. Daniel, E., G.J. Ebenezer, and C.K. Job. Pathology of iris in leprosy. Br J Ophthalmol 1997;81:(6):490-2.

54. Sivaprasad, N., S. Snehalatha, D. Lobo, M. Aschhoff, and C.K. Job. Viability of Mycobacterium leprae in lepromatous patients after five years of dapsone monotherapy supplemented with two years of multidrug therapy. Indian J Lepr 1995;67:(4):427-33.

55. Gillis, T.P. and D.L. Williams. Dapsone resistance in Mycobacterium leprae. Lepr Rev 2000;71 SupplS91-5.

56. Williams, D.L., L. Spring, E. Harris, P. Roche, and T.P. Gillis. Dihydropteroate synthase of Mycobacterium leprae and dapsone resistance. Antimicrob Agents Chemother 2000;44:(6):1530-7.

57. Shepard, C.C., J.G. Tolentino, and D.H. McRae. The therapeutic effect of 4,4'-diacetyldiamino-diphenylsulfone (DADDS) in leprosy. Am J Trop Med Hyg 1968;17:(2):192-201.

58. Chemotherapy of leprosy for control programmes. World Health Organ Tech Rep Ser 1982;6751-33.

59. Rees, R.J. Chemotherapy of leprosy for control programmes: scientific basis and practical application. Lepr Rev 1983;54:(2):81-7.

60. Ebenezer, G.J., S. Daniel, G. Norman, E. Daniel, and C.K. Job. Are viable Mycobacterium leprae present in lepromatous patients after completion of 12 months' and 24 months' multidrug therapy? Indian J Lepr 2004;76:(3):199-206.

61. Levy, L., C.C. Shepard, and P. Fasal. The bactericidal effect of rifampicin on M. leprae in man: a) single doses of 600,900 and $1200 \mathrm{mg}$; and b) daily doses of $300 \mathrm{mg}$. Int J Lepr Other Mycobact Dis 1976;44:(1-2):183-7.

62. Shetty, V.P., A. Wakade, and N.H. Antia. A high incidence of viable Mycobacterium leprae in post-MDT recurrent lesions in tuberculoid leprosy patients. Lepr Rev 2001;72:(3):337-44.

63. Ji, B., E.G. Perani, C. Petinom, L. N'Deli, and J.H. Grosset. Clinical trial of ofloxacin alone and in combination with dapsone plus clofazimine for treatment of lepromatous leprosy. Antimicrob Agents Chemother 1994;38:(4):662-7.

64. De Bruyn, E.E., H.C. Steel, E.J. Van Rensburg, and R. Anderson. The riminophenazines, clofazimine and B669, inhibit potassium transport in gram-positive bacteria by a lysophospholipid-dependent mechanism. J Antimicrob Chemother 1996;38:(3):349-62.

65. Penna, M.L., S. Buhrer-Sekula, M.A. Pontes, R. Cruz, S. Goncalves Hde, and G.O. Penna. Results from the clinical trial of uniform multidrug therapy for leprosy patients in 
Brazil (U-MDT/CT-BR): decrease in bacteriological index. Lepr Rev 2014;85:(4):262-6.

66. Butlin, C.R., D. Pahan, A.K.J. Maug, S. Withington, P. Nicholls, $\mathrm{K}$. Alam, et al. Outcome of 6 months MBMDT in MB patients in Bangladesh- preliminary results. Lepr Rev 2016;87:(2):171-82.

67. Lazo-Porras, M., G.J. Prutsky, P. Barrionuevo, J.C. Tapia, C. Ugarte-Gil, O.J. Ponce, et al. World Health Organization (WHO) antibiotic regimen against other regimens for the treatment of leprosy: a systematic review and meta-analysis. BMC Infect Dis 2020;20:(1):62.

68. Matsuoka, M., Y. Kashiwabara, and M. Namisato. A Mycobacterium leprae isolate resistant to dapsone, rifampin, ofloxacin and sparfloxacin. Int J Lepr Other Mycobact Dis 2000;68:(4):452-5.

69. Sekar, B., N. Elangeswaran, E. Jayarama, M. Rajendran, S.S. Kumar, R. Vijayaraghavan, et al. Drug susceptibility of Mycobacterium leprae: a retrospective analysis of mouse footpad inoculation results from 1983 to 1997. Lepr Rev 2002;73:(3):239-44.

70. Williams, D.L., C. Lewis, F.G. Sandoval, N. Robbins, S. Keas, T.P. Gillis, et al. Drug resistance in patients with leprosy in the United States. Clin Infect Dis 2014;58:(1):72-3.

71. Cambau, E., E. Perani, I. Guillemin, P. Jamet, and B. Ji. Multidrugresistance to dapsone, rifampicin, and ofloxacin in Mycobacterium leprae. Lancet 1997;349:(9045):103-4.

72. Ebenezer, G.J., G. Norman, G.A. Joseph, S. Daniel, and C.K. Job. Drug resistant-Mycobacterium leprae--results of mouse footpad studies from a laboratory in south India. Indian J Lepr 2002;74:(4):301-12.

73. Mahajan, N.P., M. Lavania, I. Singh, S. Nashi, V. PreethishKumar, S. Vengalil, et al. Evidence for Mycobacterium leprae Drug Resistance in a Large Cohort of Leprous Neuropathy Patients from India. Am J Trop Med Hyg 2020;102:(3):547-552.

74. Balagon, M.F., R.V. Cellona, E. Cruz, J.A. Burgos, R.M. Abalos, G.P. Walsh, et al. Long-term relapse risk of multibacillary leprosy after completion of 2 years of multiple drug therapy (WHO-MDT) in Cebu, Philippines. Am J Trop Med Hyg 2009;81:(5):895-9.

75. Shetty, V.P., M.W. Uplekar, and N.H. Antia. Primary resistance to single and multiple drugs in leprosy--a mouse footpad study. Lepr Rev 1996;67:(4):280-6.

76. Norman, G., G. Joseph, G. Ebenezer, S.P. Rao, and C.K. Job. Secondary rifampin resistance following multi-drug therapy--a case report. Int J Lepr Other Mycobact Dis 2003;71:(1):18-21.

77. Hooper, D.C. Mechanisms of action and resistance of older and newer fluoroquinolones. Clin Infect Dis 2000;31 Suppl 2S24-8.

78. Matrat, S., S. Petrella, E. Cambau, W. Sougakoff, V. Jarlier, and A. Aubry. Expression and purification of an active form of the Mycobacterium leprae DNA gyrase and its inhibition by quinolones. Antimicrob Agents Chemother 2007;51:(5):1643-8.

79. Girdhar, B.K. Fluoroquinolones and their adverse effects. Indian J Lepr 1993;65:(1):69-79.

80. Ji, B., E.G. Perani, and J.H. Grosset. Effectiveness of clarithromycin and minocycline alone and in combination against experimental Mycobacterium leprae infection in mice. Antimicrob Agents Chemother 1991;35:(3):579-81.

81. Gelber, R.H., P. Siu, M. Tsang, and L.P. Murray. Activities of various macrolide antibiotics against Mycobacterium leprae infection in mice. Antimicrob Agents Chemother 1991;35:(4):760-3.

82. Meier, A., L. Heifets, R.J. Wallace, Jr., Y. Zhang, B.A. Brown, P. Sander, et al. Molecular mechanisms of clarithromycin resistance in Mycobacterium avium: observation of multiple 23S rDNA mutations in a clonal population. J Infect Dis 1996;174:(2):354-60.

83. Gelber, R.H. Activity of minocycline in Mycobacterium lepraeinfected mice. J Infect Dis 1987;156:(1):236-9.

84. Taylor, D.E. and A. Chau. Tetracycline resistance mediated by ribosomal protection. Antimicrob Agents Chemother 1996;40:(1):1-5.
85. Ji, B., E.G. Perani, C. Petinom, and J.H. Grosset. Bactericidal activities of combinations of new drugs against Mycobacterium leprae in nude mice. Antimicrob Agents Chemother 1996;40:(2):393-9.

86. Setia, M.S., S.S. Shinde, H.R. Jerajani, and J.F. Boivin. Is there a role for rifampicin, ofloxacin and minocycline (ROM) therapy in the treatment of leprosy? Systematic review and meta-analysis. Trop Med Int Health 2011;16:(12):1541-51.

87. Villahermosa, L.G., T.T. Fajardo, Jr., R.M. Abalos, R.V. Cellona, M.V. Balagon, E.C. Dela Cruz, et al. Parallel assessment of 24 monthly doses of rifampin, ofloxacin, and minocycline versus two years of World Health Organization multi-drug therapy for multibacillary leprosy. Am J Trop Med Hyg 2004;70:(2):197-200.

88. Kumar, A., A. Girdhar, and B.K. Girdhar. A randomized controlled trial to compare cure and relapse rate of paucibacillary multidrug therapy with monthly rifampicin, ofloxacin, and minocycline among paucibacillary leprosy patients in Agra District, India. Indian J Dermatol Venereol Leprol 2015;81:(4):356-62.

89. Lockwood, D.N. and G. Cunha Mda. Developing new MDT regimens for MB patients; time to test ROM 12 month regimens globally. Lepr Rev 2012;83:(3):241-4.

90. Ebenezer, G.J. and C.K. Job. Histopathological activity in paucibacillary leprosy patients after ROM therapy. Int J Lepr Other Mycobact Dis 1999;67:(4):409-13.

91. Moet, F.J., D. Pahan, L. Oskam and J.H. Richardus. Effectiveness of single dose rifampicin in preventing leprosy in close contacts of patients with newly diagnosed leprosy: cluster randomised controlled trial. BMJ 2008;336:(7647):761-4.

92. Schoenmakers, A., L. Mieras, T. Budiawan, and W.H. van Brakel. The State of Affairs in Post-Exposure Leprosy Prevention: A Descriptive Meta-Analysis on Immuno- and Chemo-Prophylaxis. Res Rep Trop Med 2020;1197-117.

93. Lockwood, D.N.J., P. Krishnamurthy, B. Kumar, and G. Penna. Single-dose rifampicin chemoprophylaxis protects those who need it least and is not a cost-effective intervention. PLoS Negl Trop Dis 2018;12:(6):e0006403.

94. Mieras, L.F., A.T. Taal, W.H. van Brakel, E. Cambau, P.R. Saunderson, W.C.S. Smith, et al. An enhanced regimen as postexposure chemoprophylaxis for leprosy: PEP+. BMC Infect Dis 2018;18:(1):506.

95. Lipworth, B.J. Therapeutic implications of non-genomic glucocorticoid activity. Lancet 2000;356:(9224):87-9.

96. Newton, R. Molecular mechanisms of glucocorticoid action: what is important? Thorax 2000;55:(7):603-13.

97. Ayroldi, E., L. Cannarile, G. Migliorati, G. Nocentini, D.V. Delfino, and C. Riccardi. Mechanisms of the anti-inflammatory effects of glucocorticoids: genomic and nongenomic interference with MAPK signaling pathways. FASEB J 2012;26:(12):4805-20.

98. Stahn, C. and F. Buttgereit. Genomic and nongenomic effects of glucocorticoids. Nat Clin Pract Rheumatol 2008;4:(10):525-33.

99. Rao, P.S., D.S. Sugamaran, J. Richard, and W.C. Smith. Multicentre, double blind, randomized trial of three steroid regimens in the treatment of type-1 reactions in leprosy. Lepr Rev 2006;77:(1):25-33.

100. Naafs, B. Bangkok Workshop on Leprosy Research. Treatment of reactions and nerve damage. Int J Lepr Other Mycobact Dis 1996;64:(4 Suppl):S21-8.

101. Naafs, B. Treatment duration of reversal reaction: a reappraisal. Back to the past. Lepr Rev 2003;74:(4):328-36.

102. Walker, S.L., P.G. Nicholls, S. Dhakal, R.A. Hawksworth, M. Macdonald, K. Mahat, et al. A phase two randomised controlled double blind trial of high dose intravenous methylprednisolone and oral prednisolone versus intravenous normal saline and oral prednisolone in individuals with leprosy type 1 
reactions and/or nerve function impairment. PLoS Negl Trop Dis 2011;5:(4):e1041.

103. Pai, V.V., P.U. Tayshetye, and R. Ganapati. A study of standardized regimens of steroid treatment in reactions in leprosy at a referral centre. Indian J Lepr 2012;84:(1):9-15.

104. Saunderson, P., S. Gebre, K. Desta, P. Byass, and D.N. Lockwood. The pattern of leprosy-related neuropathy in the AMFES patients in Ethiopia: definitions, incidence, risk factors and outcome. Lepr Rev 2000;71:(3):285-308.

105. Croft, R.P., J.H. Richardus, and W.C. Smith. Field treatment of acute nerve function impairment in leprosy using a standardized corticosteroid regimen--first year's experience with 100 patients. Lepr Rev 1997;68:(4):316-25.

106. van Brakel, W.H. and I.B. Khawas. Nerve function impairment in leprosy: an epidemiological and clinical study--Part 2: Results of steroid treatment. Lepr Rev 1996;67:(2):104-18.

107. Richardus, J.H., S.G. Withington, A.M. Anderson, R.P. Croft, P.G. Nicholls, W.H. Van Brakel, et al. Treatment with corticosteroids of long-standing nerve function impairment in leprosy: a randomized controlled trial (TRIPOD 3). Lepr Rev 2003;74:(4):311-8.

108. Wagenaar, I., E. Post, W. Brandsma, B. Bowers, K. Alam, V. Shetty, et al. Effectiveness of 32 versus 20 weeks of prednisolone in leprosy patients with recent nerve function impairment: A randomized controlled trial. PLoS Negl Trop Dis 2017;11:(10):e0005952.

109. Smith, W.C., A.M. Anderson, S.G. Withington, W.H. van Brakel, R.P. Croft, P.G. Nicholls, et al. Steroid prophylaxis for prevention of nerve function impairment in leprosy: randomised placebo controlled trial (TRIPOD 1). BMJ 2004;328:(7454):1459.

110. Walker, S.L., E. Lebas, S.N. Doni, D.N. Lockwood, and S.M. Lambert. The mortality associated with erythema nodosum leprosum in Ethiopia: a retrospective hospital-based study. PLoS Negl Trop Dis 2014;8:(3):e2690.

111. de Barros, B., S.M. Lambert, M. Shah, V.V. Pai, J. Darlong, B.J. Rozario, et al. Methotrexate and prednisolone study in erythema nodosum leprosum (MaPs in ENL) protocol: a double-blind randomised clinical trial. BMJ Open 2020;10:(11):e037700.

112. Ramu, G. and A. Girdhar. Treatment of steroid dependant cases of recurrent lepra reaction with a combination of thalidomide and clofazimine. Lepr India 1979;51:(4):497-504.

113. Lambert, S.M., S.D. Nigusse, D.T. Alembo, S.L. Walker, P.G. Nicholls, M.H. Idriss, et al. Comparison of Efficacy and Safety of Ciclosporin to Prednisolone in the Treatment of Erythema Nodosum Leprosum: Two Randomised, Double Blind, Controlled Pilot Studies in Ethiopia. PLoS Negl Trop Dis 2016;10:(2):e0004149.

114. Lambert, S.M., D.T. Alembo, S.D. Nigusse, L.K. Yamuah, S.L. Walker, and D.N. Lockwood. A Randomized Controlled Double Blind Trial of Ciclosporin versus Prednisolone in the Management of Leprosy Patients with New Type 1 Reaction, in Ethiopia. PLoS Negl Trop Dis 2016;10:(4):e004502.

115. Marlowe, S.N., R.A. Hawksworth, C.R. Butlin, P.G. Nicholls, and D.N. Lockwood. Clinical outcomes in a randomized controlled study comparing azathioprine and prednisolone versus prednisolone alone in the treatment of severe leprosy type 1 reactions in Nepal. Trans R Soc Trop Med Hyg 2004;98:(10):602-9.

116. Sena, C.B., C.G. Salgado, C.M. Tavares, C.A. Da Cruz, M.B. Xavier, and J.L. Do Nascimento. Cyclosporine A treatment of leprosy patients with chronic neuritis is associated with pain control and reduction in antibodies against nerve growth factor. Lepr Rev 2006;77:(2):121-9.

117. Lockwood, D.N., J. Darlong, P. Govindharaj, R. Kurian, P. Sundarrao, and A.S. John. AZALEP a randomized controlled trial of azathioprine to treat leprosy nerve damage and Type 1 reactions in India: Main findings. PLoS Negl Trop Dis 2017;11:(3):e0005348.
118. Scollard, D.M., M.P. Joyce, and T.P. Gillis. Development of leprosy and type 1 leprosy reactions after treatment with infliximab: a report of 2 cases. Clin Infect Dis 2006;43:(2):e19-22.

119. Deps, P.D. and D.N. Lockwood. Leprosy occurring as immune reconstitution syndrome. Trans R Soc Trop Med Hyg 2008;102:(10):966-8.

120. Walker, S.L., A.M. Sales, C.R. Butlin, M. Shah, A. Maghanoy, S.M. Lambert, et al. A leprosy clinical severity scale for erythema nodosum leprosum: An international, multicentre validation study of the ENLIST ENL Severity Scale. PLoS Negl Trop Dis 2017;11:(7):e0005716.

121. Chan, E.S. and B.N. Cronstein. Molecular action of methotrexate in inflammatory diseases. Arthritis Res 2002;4:(4):266-73.

122. Jakeman, P. and W.C. Smith. Thalidomide in leprosy reaction. Lancet 1994;343:(8895):432-3.

123. Putinatti, M.S., J.C. Lastoria, and C.R. Padovani. Prevention of repeated episodes of type 2 reaction of leprosy with the use of thalidomide 100 mg/day. An Bras Dermatol 2014;89:(2):266-72.

124. Cogen, A.L., E. Lebas, B. De Barros, J.P. Harnisch, W.R. Faber, D.N. Lockwood, et al. Biologics in Leprosy: A Systematic Review and Case Report. Am J Trop Med Hyg 2020;102:(5):1131-1136.

125. Talwar, G.P., S.A. Zaheer, R. Mukherjee, R. Walia, R.S. Misra, A.K. Sharma, et al. Immunotherapeutic effects of a vaccine based on a saprophytic cultivable mycobacterium, Mycobacterium w in multibacillary leprosy patients. Vaccine 1990;8:(2):121-9.

126. Katoch, K., V.M. Katoch, M. Natrajan, Sreevatsa, U.D. Gupta, V.D. Sharma, et al. 10-12 years follow-up of highly bacillated BL/LL leprosy patients on combined chemotherapy and immunotherapy. Vaccine 2004;22:(27-28):3649-57.

127. Zaheer, S.A., R. Mukherjee, B. Ramkumar, R.S. Misra, A.K. Sharma, H.K. Kar, et al. Combined multidrug and Mycobacterium $w$ vaccine therapy in patients with multibacillary leprosy. J Infect Dis 1993;167:(2):401-10.

128. Duppre, N.C., L.A. Camacho, S.S. da Cunha, C.J. Struchiner, A.M. Sales, J.A. Nery, et al. Effectiveness of BCG vaccination among leprosy contacts: a cohort study. Trans R Soc Trop Med Hyg 2008;102:(7):631-8.

129. Richardus, R.A., C.R. Butlin, K. Alam, K. Kundu, A. Geluk, and J.H. Richardus. Clinical manifestations of leprosy after BCG vaccination: an observational study in Bangladesh. Vaccine 2015;33:(13):1562-7.

130. Coler, R.N., S. Bertholet, M. Moutaftsi, J.A. Guderian, H.P. Windish, S.L. Baldwin, et al. Development and characterization of synthetic glucopyranosyl lipid adjuvant system as a vaccine adjuvant. PLoS One 2011;6:(1):e16333.

131. Knudsen, N.P., A. Olsen, C. Buonsanti, F. Follmann, Y. Zhang, R.N. Coler, et al. Different human vaccine adjuvants promote distinct antigen-independent immunological signatures tailored to different pathogens. Sci Rep 2016;619570.

132. Duthie, M.S., W. Goto, G.C. Ireton, S.T. Reece, L.H. Sampaio, A.B. Grassi, et al. Antigen-specific T-cell responses of leprosy patients. Clin Vaccine Immunol 2008;15:(11):1659-65.

133. Coler, R.N., M.S. Duthie, K.A. Hofmeyer, J. Guderian, L. Jayashankar, J. Vergara, et al. From mouse to man: safety, immunogenicity and efficacy of a candidate leishmaniasis vaccine LEISH-F3+GLA-SE. Clin Transl Immunology 2015;4:(4):e35.

134. Duthie, M.S., M.T. Pena, G.J. Ebenezer, T.P. Gillis, R. Sharma, K. Cunningham, et al. LepVax, a defined subunit vaccine that provides effective pre-exposure and post-exposure prophylaxis of M. leprae infection. NPJ Vaccines 2018;312.

135. Duthie, M.S., A. Frevol, T. Day, R.N. Coler, J. Vergara, T. Rolf, et al. A phase 1 antigen dose escalation trial to evaluate safety, tolerability and immunogenicity of the leprosy vaccine candidate LepVax (LEP-F1 + GLA-SE) in healthy adults. Vaccine 2020;38:(7):1700-1707. 
136. Job, C.K. and C.J. Chacko. A modification of Fite's stain for demonstration of M. leprae in tissue sections. Indian J Lepr 1986;58:(1):17-8.

137. Nayak, S.V., A.S. Shivarudrappa, and A.S. Mukkamil. Role of fluorescent microscopy in detecting Mycobacterium leprae in tissue sections. Ann Diagn Pathol 2003;7:(2):78-81.

138. Natrajan, M., K. Katoch, V.M. Katoch, and V.P. Bharadwaj. Enhancement in the histological diagnosis of indeterminate leprosy by demonstration of mycobacterial antigens. Acta Leprol 1995;9:(4):201-7.

139. Job, C.K., V. Drain, A.T. Deming, R.C. Hastings, and M.A. Gerber. Role of S-100 protein as a marker for Schwann cells in the diagnosis of tuberculoid leprosy. Int J Lepr Other Mycobact Dis 1990;58:(2):392-3.

140. Truman, R.W., C.K. Job, and R.C. Hastings. Antibodies to the phenolic glycolipid-1 antigen for epidemiologic investigations of enzootic leprosy in armadillos (Dasypus novemcinctus). Lepr Rev 1990;61:(1):19-24.

141. Thomas, M.M., M. Jacob, S.M. Chandi, S. George, S. Pulimood, L. Jeyaseelan, et al. Role of S-100 staining in differentiating leprosy from other granulomatous diseases of the skin. Int J Lepr Other Mycobact Dis 1999;67:(1):1-5.

142. Truman, R.W., G.J. Ebenezer, M.T. Pena, R. Sharma, G. Balamayooran, T.H. Gillingwater, et al. The armadillo as a model for peripheral neuropathy in leprosy. ILAR J 2014;54:(3):304-14.

143. Stefani, M.M.A., C. Avanzi, S. Buhrer-Sekula, A. Benjak, C. Loiseau, P. Singh, et al. Whole genome sequencing distinguishes between relapse and reinfection in recurrent leprosy cases. PLoS Negl Trop Dis 2017;11:(6):e0005598.

144. Ooi, W. and S. Saini. Diagnostic Pitfalls in an Atypical Case of Primary Neuritic Leprosy. Am J Trop Med Hyg 2021.

145. Lockwood, D.N., S.B. Lucas, K.V. Desikan, G. Ebenezer, S. Suneetha, and P. Nicholls. The histological diagnosis of leprosy type 1 reactions: identification of key variables and an analysis of the process of histological diagnosis. J Clin Pathol 2008;61:(5):595-600.

146. Lauria, G., S.T. Hsieh, O. Johansson, W.R. Kennedy, J.M. Leger, S.I. Mellgren, et al. European Federation of Neurological Societies/ Peripheral Nerve Society Guideline on the use of skin biopsy in the diagnosis of small fiber neuropathy. Report of a joint task force of the European Federation of Neurological Societies and the Peripheral Nerve Society. Eur J Neurol 2010;17:(7):903-12, e44-9.

147. Mangus, L.M., D.B. Rao, and G.J. Ebenezer. Intraepidermal Nerve Fiber Analysis in Human Patients and Animal Models of Peripheral Neuropathy: A Comparative Review. Toxicol Pathol 2020;48:(1):59-70.

148. Ebenezer, G.J., P. Hauer, C. Gibbons, J.C. McArthur, and M. Polydefkis. Assessment of epidermal nerve fibers: a new diagnostic and predictive tool for peripheral neuropathies. J Neuropathol Exp Neurol 2007;66:(12):1059-73.

149. Rodrigues Junior, I.A., I.C. Silva, L.T. Gresta, S. Lyon, F. Villarroel Mde, and R.M. Arantes. Degree of skin denervation and its correlation to objective thermal sensory test in leprosy patients. PLoS Negl Trop Dis 2012;6:(12):e1975.

150. Facer, P., D. Mann, R. Mathur, S. Pandya, U. Ladiwala, B. Singhal, et al. Do nerve growth factor-related mechanisms contribute to loss of cutaneous nociception in leprosy? Pain 2000;85:(1-2):231-8.

151. Antunes, S.L., Y. Liang, J.A. Neri, M. Haak-Frendscho, and O. Johansson. The expression of NGFr and PGP 9.5 in leprosy reactional cutaneous lesions: an assessment of the nerve fiber status using immunostaining. Arq Neuropsiquiatr 2003;61:(2B):346-52.

152. Karanth, S.S., D.R. Springall, S. Lucas, D. Levy, P. Ashby, M.M. Levene, et al. Changes in nerves and neuropeptides in skin from 100 leprosy patients investigated by immunocytochemistry. J Pathol 1989; 157:(1):15-26.
153. Van Brakel, W.H., P.G. Nicholls, L. Das, P. Barkataki, P. Maddali, D.N. Lockwood, et al. The INFIR Cohort Study: assessment of sensory and motor neuropathy in leprosy at baseline. Lepr Rev 2005;76:(4):277-95.

154. van Brakel, W.H., P.G. Nicholls, E.P. Wilder-Smith, L. Das, P. Barkataki, and D.N. Lockwood. Early diagnosis of neuropathy in leprosy--comparing diagnostic tests in a large prospective study (the INFIR cohort study). PLoS Negl Trop Dis 2008;2:(4):e212.

155. Kumar, N., H.S. Malhotra, R.K. Garg, R. Lalla, K.P. Malhotra, A. Jain, et al. Comprehensive electrophysiology in leprous neuropathy - Is there a clinico-electrophysiological dissociation? Clin Neurophysiol 2016;127:(8):2747-2755.

156. Chaurasia, R.N., R.K. Garg, M.K. Singh, R. Verma, and R. Shukla. Nerve conduction studies in paucibacillary and multibacillary leprosy: a comparative evaluation. Indian J Lepr 2011;83:(1):15-22.

157. Husain, S. and G.N. Malaviya. Early nerve damage in leprosy: an electrophysiological study of ulnar and median nerves in patients with and without clinical neural deficits. Neurol India 2007;55:(1):22-6.

158. Samant, G., V.P. Shetty, M.W. Uplekar, and N.H. Antia. Clinical and electrophysiological evaluation of nerve function impairment following cessation of multidrug therapy in leprosy. Lepr Rev 1999; 70:(1):10-20.

159. Soysal, A., T. Atay, T. Ozu, and B. Arpaci. Electrophysiological evaluation of peripheral and autonomic involvement in leprosy. Can J Neurol Sci 2004;31:(3):357-62.

160. Villarroel, M.F., M.B. Orsini, M.A. Grossi, and C.M. Antunes. Impaired warm and cold perception thresholds in leprosy skin lesions. Lepr Rev 2007;78:(2):110-21.

161. Jain, S., L.H. Visser, T.L. Praveen, P.N. Rao, T. Surekha, R. Ellanti, et al. High-resolution sonography: a new technique to detect nerve damage in leprosy. PLoS Negl Trop Dis 2009;3:(8):e498.

162. Lugao, H.B., M.H. Nogueira-Barbosa, W. Marques, Jr., N.T. Foss, and M.A. Frade. Asymmetric Nerve Enlargement: A Characteristic of Leprosy Neuropathy Demonstrated by Ultrasonography. PLoS Negl Trop Dis 2015;9:(12):e0004276.

163. Martinoli, C., L.E. Derchi, M. Bertolotto, N. Gandolfo, S. Bianchi, P. Fiallo, et al. US and MR imaging of peripheral nerves in leprosy. Skeletal Radiol 2000;29:(3):142-50.

164. Akita, J., L.H.G. Miller, F.M.C. Mello, J.A. Barreto, A.L. Moreira, M.H. Salgado, et al. Comparison between nerve conduction study and high-resolution ultrasonography with color doppler in type 1 and type 2 leprosy reactions. Clin Neurophysiol Pract 2021;697-102.

165. Sreejith, K., S. Sasidharanpillai, K. Ajithkumar, R.M. Mani, A.T. Chathoth, P.S. Menon, et al. High-resolution ultrasound in the assessment of peripheral nerves in leprosy: A comparative cross-sectional study. Indian J Dermatol Venereol Leprol 2021;87:(2):199-206.

166. Illarramendi, X., S. Buhrer-Sekula, A.M. Sales, M.I. Bakker, A. Oliveira, J.A. Nery, et al. High prevalence of vasomotor reflex impairment in newly diagnosed leprosy patients. Eur J Clin Invest 2005;35:(10):658-65.

167. Cavalheiro, A.L., D.T. Costa, A.L. Menezes, J.M. Pereira, and E.M. Carvalho. Thermographic analysis and autonomic response in the hands of patients with leprosy. An Bras Dermatol 2016;91:(3):274-83.

168. Beck, J.S., N.C. Abbot, P.D. Samson, C.R. Butlin, J.M. Grange, I.A. Cree, et al. Impairment of vasomotor reflexes in the fingertips of leprosy patients. J Neurol Neurosurg Psychiatry 1991;54:(11):965-71.

Publisher's Note Springer Nature remains neutral with regard to jurisdictional claims in published maps and institutional affiliations. 